\title{
Acesso à justiça: um debate inacabado ${ }^{1}$
}

\author{
Access to justice: an unfinished debate
}

Acceso a la justicia: un debate inacabado

\author{
Rebecca Lemos Igreja ${ }^{2}$ \\ Universidade de Brasília (Brasília, DF, Brasil) \\ ORCID: https://orcid.org/0000-0002-9533-2985 \\ E-mail: rebecca.igreja@gmail.com
}

Talita Tatiana Dias Rampin ${ }^{3}$

Universidade de Brasília (Brasília, DF, Brasil) ORCID: https://orcid.org/0000-0003-0487-4795

E-mail: talitarampin@gmail.com

\section{Resumo}

Nos últimos anos, assistimos ao aumento do interesse no debate sobre "acesso à justiça”. O tema está presente nas agendas nacionais e internacionais das discussões sobre as reformas judiciais, especialmente na América Latina. Neste artigo, propomos retomar o debate sobre o acesso à justiça, especificamente, sobre a concepção mesma de acesso à justiça, seus significados, sua delimitação e o conceito de justiça que incorpora. Iniciamos por uma análise sobre como o tema tem sido abordado, especialmente no contexto latino-americano. Em seguida, com base em uma experiência de pesquisas realizadas por nós e por outros especialistas

\footnotetext{
1 IGREJA, Rebecca Lemos; RAMPIN, Talita Tatiana Dias. Acesso à justiça: um debate inacabado. Suprema: revista de estudos constitucionais, Brasília, v. 1, n. 2, p. 191-220, jul./dez. 2021.

${ }^{2}$ Doutora em Antropologia e professora da Faculdade de Direito (Universidade de Brasília, Brasil); coordenadora do Colégio Latino-americano de Estudos Mundiais (FLACSO/Brasil) e pesquisadora do Laboratório de Acesso à Justiça e Desigualdades (LADES/PPGD/UNB). Pesquisadora associada ao Centre d'étude des mouvements sociaux (CEMS/ EHESS/França). Membro e integrante da Comissão diretiva da Rede de Estudos Empíricos do Direito - REED (Brasil) e do Justice For Afrodescendants In Latin America Institute OJALA (Florida International University [FIU]). Cocoordenadora do International Research Collaborative (IRC) da Law and Society (Estados Unidos). Pesquisadora associada à Rede Latino-americana de Antropologia Jurídica - RELAJU; Editora-chefe da Abya-Yala: Revista sobre acesso à Justiça e direitos nas Américas. Currículo Lattes: http://lattes.cnpq.br/3708348431238743.

3 Doutora em Direito e professora da Faculdade de Direito (Universidade de Brasília, Brasil) e pesquisadora do Colégio Latino-americano de Estudos Mundiais (FLACSO/Brasil) e coordenadora do Laboratório de Acesso à Justiça e Desigualdades (LADES/PPGD/UNB), Editora-chefe da Abya-Yala: Revista sobre acesso à Justiça e direitos nas Américas; coordenadora do International Research Collaborative (IRC) da Law and Society (Estados Unidos) e pesquisadora do Instituto de Pesquisa, Direitos e Movimentos Sociais. Currículo Lattes: http://lattes.cnpq. br/0580866422834132.
} 
do tema, aprofundamos na análise. Concluímos com a apresentação do nosso entendimento sobre o acesso à justiça, uma perspectiva que propõe reconhecer uma pluralidade de sentidos de justiça e de direitos, compreendidos de forma ampla e em conexão com diferentes entendimentos, fruto das particularidades sociais e culturais da sociedade. Trata-se de uma concepção de acesso à justiça, não apenas como um movimento de institucionalização, mas também como uma transformação do espaço jurídico, onde a justiça se realiza.

\section{Palavras-chave}

Acesso à justiça; América Latina; Sistema de justiça; Pesquisa empírica; Poder Judiciário.

\section{Suimário}

1. Introdução. 2. Revisitando os estudos sobre acesso à justiça. 3. Redefinindo o acesso à justiça: a contribuição das pesquisas empíricas, da formação jurídica e as atividades de assistência comunitária. 4. Conclusão.

\section{Abstract}

In recent years, we have seen an increase in interest in the debate on "access to justice". The theme is present in the national and international agendas of discussions on judicial reforms, especially in Latin America. In this article, we propose to resume the debate on access to justice, specifically, on the very conception of access to justice, its meanings, its delimitation, and the concept of justice that it incorporates. We begin with an analysis of how the topic has been approached, especially in the Latin American context. Then, based on an experience of research carried out by us and other specialists on the subject, we went deeper into the analysis. We conclude with the presentation of our understanding of access to justice, a perspective that proposes to recognize a plurality of meanings of justice and rights, understood broadly and in connection with different understandings, as a result of the social and cultural particularities of society. It is a conception of access to justice, not only as an institutionalization movement, but also as a transformation of the legal space, where justice takes place.

\section{Keywords}

Access to justice; Latin America; Justice system; Empirical research; Judicial power. 


\section{Contents}

1. Introduction. 2. Revisiting studies on access to justice. 3. Redefining access to justice: the contribution of empirical research, legal education and community assistance activities. 4. Conclusion.

\section{Resumen}

En los últimos años, hemos visto un aumento del interés en el debate sobre el "acceso a la justicia". El tema está presente en las agendas nacionales e internacionales de discusiones sobre reformas judiciales, especialmente en América Latina. En este artículo nos proponemos retomar el debate sobre el acceso a la justicia, específicamente, sobre la propia concepción del acceso a la justicia, sus significados, su delimitación y el concepto de justicia que incorpora. Comenzamos con un análisis de cómo se ha abordado el tema, especialmente en el contexto latinoamericano. Luego, a partir de una experiencia de investigación realizada por nosotros y otros especialistas en el tema, profundizamos nuestro análisis. Concluimos con la presentación de nuestra comprensión del acceso a la justicia, perspectiva que propone reconocer una pluralidad de significados de justicia y derechos, entendidos de manera integral y en conexión con diferentes entendimientos, fruto de las particularidades sociales y culturales de la sociedad. Es una concepción del acceso a la justicia, no solo como un movimiento de institucionalización, sino también como una transformación del espacio donde se realiza la justicia.

\section{Palabras clave}

Acceso a la justicia; América Latina; Sistema de justicia; Investigación empírica; Poder Judicial.

\section{Índice}

1. Introducción. 2. Revisando los estudios sobre acceso a la justicia. 3. Redefiniendo el acceso a la justicia: el aporte de la investigación empírica, la formación jurídica y las actividades de asistencia comunitaria. 4. Conclusión. 


\section{Introdução}

Nos últimos anos, assistimos ao aumento do interesse no debate sobre "acesso à justiça". O tema está presente nas agendas nacionais e internacionais das discussões sobre as reformas judiciais, especialmente na América Latina. É reforçado por instâncias internacionais como o Banco Mundial e a Organização para a Cooperação e Desenvolvimento Econômico (OCDE), entre outras, e está na pauta dos diversos grupos e centros de pesquisa sobre os sistemas de justiça e poder judicial (RAMPIN, 2018; GARTH, 2009; IGREJA; RAMPIN, 2021a). Esse novo interesse, no entanto, nem sempre traz novas discussões para o debate, e muitas das análises que observamos ainda estão baseadas em um pré-entendimento, que precisa ser revisitado, sobre o que é justiça. Além disso, o acesso à justiça costuma ser compreendido apenas como acesso ao poder judicial, delimitando sua potencialidade para responder aos desafios atuais de nossa sociedade ${ }^{4}$.

De maneira particular, acompanhamos esse ressurgir do tema a partir de uma perspectiva latino-americana crítica, regional e empiricamente situada, levando em consideração as especificidades dos mais diversos contextos. Nos últimos anos, temos desenvolvido estudos com o objetivo de contribuir para que a análise sobre o acesso à justiça se estenda para além do poder judicial e respectivos procedimentos e instrumentos necessários para movimentá-lo ou nele adentrar (IGREJA; RAMPIN, 2012, 2021a). São pesquisas realizadas em campos interdisciplinares de estudo em contextos diferenciados, como, por exemplo, estudos voltados para a análise do pluralismo jurídico, fruto da convivência de dois sistemas jurídicos reconhecidos constitucionalmente em um mesmo Estado, e estudos sobre o poder judiciário e seus atores principais, assim como sobre justiças alternativas e assistências jurídicas populares.

De maneira específica, nossas análises se baseiam em pesquisas anteriores no México, a partir dos anos 1990, sobre o acesso à justiça da população indígena mexicana, com destaque para a residente na Cidade do México ${ }^{5}$. Essa presença

\footnotetext{
4 Este artigo é resultado de uma série de debates que aconteceram durante a Escola de Altos Estudos sobre Desigualdades Globais e Justiça Social, organizada pela Faculdade de Direito da Universidade de Brasília e pelo Colégio Latino-americano de Estudos Mundiais da FLACSO/Brasil, no ano de 2019 e 2020. Agradecemos, de maneira especial, aos comentários do prof. Bryant Garth e da prof. Rebecca Sandefur, dos Estados Unidos, que estiveram presentes conosco em nossa discussão.

${ }_{5}$ Os dados mais recentes indicam que, em 2010, havia 122.411 pessoas de 5 anos ou mais que falam uma língua indígena na Cidade do México. Esse número deve ser tomado sob certas reservas, pois há uma tendência a subestimar a população indígena. Os números apresentados por diversas instituições podem chegar a 500.000 indígenas no contexto da cidade (IGREJA, 2019, 2020).
} 
indígena mexicana traz interrogantes importantes sobre o acesso à justiça, especialmente quando a Constituição Nacional Mexicana e, em particular, a Constituição da Cidade do México reconhecem os sistemas normativos próprios dos indígenas ${ }^{6}$. Esse reconhecimento de sistemas de justiça diferenciados em um mesmo contexto estatal exige permanente adequações e negociações entre os dois sistemas, até mesmo no que diz respeito às responsabilidades decisórias de cada um.

Nesse rol de pesquisas, incluímos, igualmente, as realizadas pelo Instituto de Pesquisa Econômica Aplicada (IPEA) sobre o acesso à justiça nos juizados especiais federais (INSTITUTO..., 2012) e sobre a política criminal alternativa à prisão (INSTITUTO..., 2015), que foram financiadas pelo Conselho de Justiça Federal e pelo Conselho Nacional de Justiça, complementadas por pesquisas sobre desigualdades, discriminação e racismo no sistema de justiça, as quais realizamos no âmbito de instituições de ensino.

Atualmente, desenvolvemos uma pesquisa internacional, envolvendo o contexto europeu, norte-americano e latino-americano, sobre radicalismos políticos, extrema-direita e sistema de justiça (IGREJA, 2020), que está inserida nas atividades do International Research Collaborative (IRC), intitulada Political Radicalisms, Extreme-Right, and Justice System, que coordenamos na Law and Society ${ }^{7}$. Além disso, também estamos conduzindo estudos relacionados à identificação dos impactos da pandemia no acesso à justiça no Brasil (IGREJA; RAMPIN, 2021), que tanto envolve a análise da prestação jurisdicional e a constituição de um campo jurídico específico, mais recentemente associado à noção da covid-law, como inclui a exploração de experiências diversificadas de práticas jurídicas no âmbito da assistência jurídica (RAMPIN, 2020).

Todas essas pesquisas foram e estão sendo realizadas com amplos trabalhos de campo, com a utilização de metodologias qualitativas e quantitativas comparativas e interdisciplinares (IGREJA, 2017), e envolvem a triangulação de dados,

\footnotetext{
${ }^{6}$ Uma nova reforma legislativa importante surgiu com a elaboração da nova Constituição da Cidade do México CDMX em 2018. A cidade deixa de ser um distrito federal, consolidando-se como mais um estado do país, e elabora sua constituição estadual, aprovada em sua totalidade por uma Assembleia Constituinte em 31 de janeiro de 2017. Necessário explicar que o sistema federativo mexicano atribui aos estados a competência e maior autonomia para elaborarem seus próprios códigos civis e legislarem sobre assuntos que não estejam especificados na Constituição Federal ou que sejam por ela autorizados. Por essa razão, foi possível que a nova Constituição da Cidade do México contemplasse vários direitos para as comunidades indígenas residentes, especialmente o direito amplo à autonomia jurídica e política, direitos esses não reconhecidos totalmente em várias entidades federativas do país (IGREJA, 2019, 2020).
}

Disponível em: https://lawandsociety.site-ym.com/. 
o desenvolvimento de estudos de caso, a realização de entrevistas, a análise de documentos, entre outras técnicas.

Esses anos dedicados a essas pesquisas e as discussões que tivemos oportunidade de estabelecer com outros especialistas sobre o tema levaram-nos a concluir que uma abordagem que privilegie somente a perspectiva do acesso como sendo a capacidade de ingresso ao poder judiciário não permite tratar a dimensão social que o envolve. Além disso, acaba por refletir e propagar uma perspectiva monista do direito, que pressupõe a exclusiva mediação do Estado para estabelecer e reconhecer direitos e resolver conflitos em uma determinada sociedade. Da mesma forma, ignora a diversidade de contextos sociais, culturais e econômicos em que a justiça estatal atua. Trata-se de uma abordagem, geralmente, limitada, e que não dá conta da diversidade de experiências no acesso e dos sentidos de justiça e direito existentes.

Neste artigo, tomamos como problema, portanto, o trabalho de revisitar, de forma crítica, a discussão sobre o acesso à justiça, analisando, a partir de revisão teórica, a sua origem como conceito e as formas como tem sido tratado pelas diversas perspectivas teóricas, metodológicas e disciplinares, especialmente, latino-americanas. A partir dessa análise e tendo como pano de fundo o acúmulo de pesquisa empíricas no campo temático, propomos, neste texto, avançar na concepção de acesso à justiça, não apenas como um movimento de institucionalização, mas, também, como uma transformação do espaço jurídico, onde a busca pela justiça e a garantia de direitos se realizam. Adotamos uma perspectiva que propõe reconhecer uma pluralidade de sentidos de justiça e de direitos, compreendidos de forma ampla e em conexão com diferentes entendimentos, fruto das particularidades sociais e culturais da sociedade.

Recolocar a discussão sobre o acesso à justiça é uma tarefa relevante, diante das permanentes mudanças dos contextos socioculturais e político-econômicos que interpelam diretamente a própria ideia de justiça, do justo e do injusto. É importante considerarmos o contexto atual marcado pela globalização, onde observamos uma maior inter-relação entre as diferentes nações, a consolidação de um sistema econômico transnacional e uma maior circulação de ideias e de pessoas, entre outros fenômenos. Acompanha esse contexto o surgimento de propostas de renovação dos sistemas de justiça, internacionais e nacionais, buscando maior eficácia, agilidade e garantia de direitos, especialmente mediante a modernização e digitalização de seus processos. Essas propostas, no entanto, continuam enfrentando desafios antigos, como a desigualdade global e nacional, 
as diferenças regionais, sociais e culturais existentes, assim como as demandas de reconhecimento de diversos coletivos. São situações que interpelam não somente o acesso à justiça, como, também, a própria concepção do justo e do injusto e o papel do poder judiciário como garantidor de uma justiça inclusiva.

\section{Revisitando os estudos sobre acesso à justiça}

Como tema de pesquisa, o acesso à justiça tem sido abordado a partir de diferentes perspectivas, especialmente, oriundas do campo das ciências sociais. $\mathrm{Na}$ área do direito, mais especificamente, no conjunto de estudos empíricos sobre o tema, destacamos as contribuições de Mauro Cappelletti e Bryant G. Garth, que desenvolveram, na década de 1970, uma ampla pesquisa comparativa entre diferentes países e sistemas jurídicos, a partir da qual propuseram uma teoria explicativa inovadora, que ficou mundialmente conhecida como a teoria das ondas de renovação do acesso à justiça (CAPELLETTI; GARTH, 1988). Essas ondas, segundo formulação dos autores, refletiriam os esforços para garantir ajuda jurídica aos pobres (primeira onda), a representação de interesses difusos (segunda onda) e o acesso à representação jurídica a um conceito mais amplo de acesso à justiça, por exemplo, os holofotes sobre a eficácia do processo (terceira onda).

Essas ondas, igualmente, segundo levantamento realizado pela pesquisadora Eliane Botelho Junqueira (1996), não refletiriam, com exatidão, o percurso dos temas estudados no Brasil, quando analisamos a produção acadêmica nacional, no mesmo período. Isso porque, no País, os pesquisadores tinham, em seu horizonte, a necessidade de estudar o acesso coletivo à justiça e as questões relacionadas ao acesso individual ao sistema de resolução de disputas, tendo como pano de fundo a inacessibilidade da justiça para os setores populares. No período, portanto, em que Cappelletti e Garth identificaram o movimento internacional de acesso à justiça, vivenciávamos, no Brasil, uma outra realidade, que levou pesquisadores, tais como Boaventura de Sousa Santos, Cecília McDowell, Joaquim Falcão e Luciano Oliveira, a se dedicarem a demandas emergidas da realidade social e que envolviam, até mesmo, o pluralismo jurídico e as formas de organização social identificadas.

Apesar da grande difusão dos estudos de Cappelletti e Garth (1988), temos pouca repercussão, no Brasil, de outro estudo bastante importante realizado por Bryant Garth juntamente com Yves Dezalay, expresso em um texto que trata o acesso como fenômeno social, a partir da teoria do campo social de Pierre 
Bourdieu. Este estudo intitulado "The internationalization of palace wars: lawyers, economists and the contest to transform Latin American states" (DEZALAY; GARTH, 2002) dialoga com a nossa perspectiva relativa à importância de refletirmos sobre como a desigualdade permeia o espaço da justiça.

Em anos mais recentes, novos estudos foram surgindo, com destaque para aqueles propostos por pesquisadores estadunidenses. Debora L. Rhode (2013), por exemplo, vincula esse surgimento à recessão econômica da última década, que criou a necessidade de se proporcionar maior acesso aos serviços legais para as diversas populações estadunidenses carecentes de serviços sociais. Uma demonstração dessa necessidade, segundo a autora, foi a proposta da Iniciativa de Acesso à Justiça pelo Departamento de Justiça dos Estados Unidos (Access to Justice Iniciative in the United States Department of Justice) durante a administração do presidente Barack Obama, que resultou na constituição de um consórcio sobre acesso à justiça, com o objetivo de realizar pesquisas e promover formação sobre o tema. Com base no relatório desse consórcio, Rhode procura sistematizar o que seria uma agenda de estudos sobre o acesso à justiça.

Como Rhode explica e, aqui, resumimos, uma das questões que se destaca no debate sobre o tema é a falta de transparência sobre a que se busca oferecer acesso: a uma justiça no sentido processual, como o acesso à assistência jurídica e aos processos legais que se dirijam a problemas possíveis de tratamento legal? Ou a uma justiça em um sentido substantivo, como a uma resolução justa de disputas legais e problemas sociais? Segundo a autora, os participantes do consórcio apresentaram diferentes concepções de justiça e as melhores estratégias para promovê-la. Deborah L. Rhode segue em seu texto apresentando as diferentes perspectivas que comporiam essa agenda de estudo, como a abordagem comum de promoção de estudos amostrais com população de baixa renda, para questionar se ela já teve problemas que poderiam ser solucionados pela lei e como ela buscou soluções para eles. Em sua análise, embora úteis até certo ponto, esses estudos também têm limites inerentes. Eles, provavelmente, subestimam a necessidade não atendida, porque dependem de percepções subjetivas de problemas individuais, quando, em realidade, muitos indivíduos podem desconhecer os seus direitos e as soluções possíveis para os seus problemas. Outras abordagens põem em análise a falta de serviços legais, custos e acessibilidade para as populações vulneráveis. Rhode discute, no entanto, que essas pesquisas têm limitações próprias e são, ainda, em pequeno número para alcançar uma perspectiva ampla sobre o tema. Para ela, um dos problemas centrais é a falta de apoio para a realização de pesquisas empíricas e a promoção de uma educação 
jurídica, que auxiliem no entendimento e na solução de problemas que dificultam o acesso à justiça. (RHODE, 2013)

Podemos, ainda, trazer como exemplo de abordagem o artigo de Trevor C. W. Farrow (2014), no qual o autor pergunta o que é acesso à justiça e propõe uma perspectiva em que o enfoque seja dado àqueles que usam o sistema, ou seja, ao público. No artigo, o autor apresenta dados de sua pesquisa empírica realizada em Toronto, entre os anos de 2012 e 2013, que teve como base entrevistas com membros da população da cidade, em lugares públicos, sobre como eles definiam justiça e o seu acesso. Os dados trazem informações relevantes sobre as percepções, os sentidos de justiça para essas pessoas e as dificuldades que enfrentam para um devido acesso à justiça e garantia de seus direitos.

Outra autora que destacamos nesse cenário é Rebecca Sandefur (2018), cujos estudos vêm reforçar a crítica sobre a forma como as desigualdades podem permear o acesso à justiça. Sandefur explica que, atualmente, o acesso à justiça está restrito a determinadas pessoas e tipos de problemas. Nesse sentido, observa que a solução comumente pensada para resolver essa desigualdade no acesso é a ampliação da oferta de serviços legais. Pondera, no entanto, com base em análises empíricas sobre "problemas de justiça” ou "casos justiciáveis", que o foco sobre o acesso à justiça deveria se concentrar nas experiências das pessoas, em como vivem e enfrentam os problemas que envolvem questões de justiça e de que tipo de assistência legal necessitam. Assim, seria uma perspectiva que considera as experiências que as pessoas têm com o sistema de justiça, com as organizações ou instituições, e teria como foco observar quem tem acesso às instituições e que tipo de resultado obtêm. Além disso, a autora reflete sobre como ocorre o acesso à justiça considerando as diferenças de classe social, gênero e raça.

Os estudos sobre acesso à justiça também estão presentes na América Latina e envolvem uma ampla gama de pesquisas sobre o sistema de justiça, promovidas por diferentes disciplinas. No Brasil, a pesquisa sociológica sobre o tema foi conduzida a partir da década de 1980, com estudos dedicados à experiência popular de estruturação de sistemas político-regulatórios, que permanecem como esquemas paralelos ao escopo da incidência estatal (SANTOS, 1986), e outros dedicados à análise de formas de administração estatal de conflitos surgidos da realidade (SADEK, 2001). Na antropologia do direito, por sua vez, está concentrada em estudos de instituições judiciárias, órgãos judiciais, estudos de segurança pública, especialmente sobre polícia, e em estudos comparativos de sistemas de justiça, entre outros (LIMA, 1999, 2008, 2013). 
É importante situarmos que a antropologia jurídica latino-americana se desenvolverá a partir de paradigmas analíticos sobre o fenômeno jurídico, em duas perspectivas diferentes (COMAROFF; SIMON, 1981). Os estudos antropológicos passaram a se dedicar à análise de sistemas jurídicos das sociedades tradicionais e, mais recentemente, das sociedades ocidentais. Esses estudos estão concentrados, por um lado, nas normas e nos estudos das instituições em sociedades não ocidentais e, por outro lado, nas análises dos processos sociais e legais, como processos de resolução de controvérsias, nos quais as normas são materializadas (CHENAUT; SIERRA, 2006).

Especialmente desde a década de 1980, na América Latina, novos estudos surgiram com a finalidade de analisar o encontro de diferentes sistemas jurídicos, no mesmo campo social, e suas implicações sociais e políticas. Esse encontro configura um pluralismo legal constituído pela preservação das formas jurídicas tradicionais, especialmente observadas em povos indígenas que sofreram $o$ processo de colonização, ou mesmo pela existência de múltiplas regulamentações presentes nas sociedades modernas. (CHENAUT, SIERRA, 2006; MOORE, 1986; STAVENHAGEN; ITURRALDE, 1990).

Os estudos sobre pluralismo jurídico são importantes para demonstrar como se constituem essas arenas de disputas e negociações no campo do acesso à justiça na América Latina, que não se restringem apenas ao âmbito da justiça formal ocidental, monista, ao contrário, colocam em evidência o confronto entre concepções do direito, autônomas e distintas. Desde os anos 1990, com o advento das reformas e as novas Constituições latino-americanas que reconheceram, em forma de lei, o caráter multicultural e plurinacional de vários países do continente, o debate sobre os direitos indígenas esteve em pauta, abrindo espaço para as demandas específicas dessa população, como a reivindicação de autonomia e autodeterminação.

O pluralismo jurídico é uma perspectiva de grande importância analítica e política para compreender as relações que se estabelecem entre o Estado de Direito e os povos indígenas na América Latina. E, além de figurar, no Brasil, na gênese dos estudos sobre o acesso à justiça, tem sido pensado como marco analítico para compreender a diversidade dos sistemas jurídicos indígenas e sua validade no mundo contemporâneo, bem como sua conexão no âmbito das constelações legais das quais esses sistemas fazem parte. É, igualmente, um instrumento a partir do qual pode se dar o aprimoramento das lutas indígenas pela autonomia nos espaços judiciais nacionais e internacionais, bem como um 
impulso ao fortalecimento e à recriação do próprio direito indígena (SIERRA; IGREJA, 2020).

Embora seja uma luta desigual, dadas as assimetrias de poder, os povos indígenas têm gerado alternativas para defender seus direitos e suas identidades coletivas, assim como suas próprias racionalidades jurídicas reconhecidas no marco internacional dos direitos humanos (STAVENHAGEN, 2010). Dessa forma, eles ativam configurações jurídicas plurais em um contexto de aumento das desigualdades, da violência e da criminalização de suas existências e lutas. Como parte desses processos de resistência, diversas análises demonstram como os diferentes povos indígenas se movem entre os variados níveis legais, desde os locais aos mais globais, em busca de garantir os seus direitos, e como eles se apropriam de novas linguagens, mobilizando-as para avançar na luta pela justiça. Nesse sentido, utilizam as leis que os subordinam e, muitas vezes, discriminam, a seu próprio favor, apelando aos sistemas de direitos humanos e às legislações e convenções internacionais de proteção aos povos originários, para garantir os seus próprios direitos, suas formas de vida e seus territórios.

O uso do conceito “direito indígena” restitui o espaço jurídico que essas normatividades indígenas ocupam em relação à justiça do Estado. Opõe-se, igualmente, ao discurso que reconhece apenas a justiça estatal e que legitima a dominação e a subordinação de outros povos, em contextos marcados por processos históricos de colonização e de profundas desigualdades (IGREJA; SIERRA, $2020^{8}$ ). Importante, no entanto, especificar que afirmar a existência de sistemas jurídicos plurais, o indígena e o estatal, não deve ser interpretado como duas instâncias separadas, pois ambas se encontram entrelaçadas e moldadas por histórias de dominação e colonização, sempre em diálogo e influenciando uma na outra (SIERRA, 2004; IGREJA; SIERRA, 2020). É necessário analisar, do mesmo modo, como a lei estatal penetra e reconstrói as diversas normas sociais, por meios simbólicos e coercitivos, à medida que a resistência a elas é gerada, e como a lei estatal é, ela mesma, modificada (MERRY, 1988; STARR; COLLIER, 1995).

Boaventura de Sousa Santos (1986), ao discutir o desenvolvimento de estudos na área do pluralismo, indica que seu advento ocorreu no período seguinte à Segunda Guerra Mundial (1939-1945), no qual houve uma mudança

${ }^{8}$ Nesses dois artigos, Sierra e Igreja analisam amplamente as perspectivas do pluralismo jurídico na América Latina, debatendo seus desafios e limites no contexto atual (IGREJA; SIERRA, 2020). 
na "conjuntura intelectual" para a qual convergiram três "condições teóricas" e duas "condições sociais". No campo teórico da análise, aponta o desenvolvimento de estudos sobre direito e justiça realizados a partir da sociologia das organizações, ciência política e antropologia do direito ou etologia jurídica (SANTOS, 1986, p. 14-15). No âmbito social, destaca as “[...] lutas sociais realizadas por grupos sociais que, até então, não tinham tradição histórica de ação coletiva de confronto [...]", e a "crise da administração da justiça", vivenciada na década de 1960 (SANTOS, 1986, p. 15-16).

Ainda sobre pluralismo, destacam-se os trabalhos clássicos de Antonio Carlos Wolkmer (2019), os quais apresentam uma crítica à insuficiência do direito de tradição etnocêntrica ocidental e propõem um contraponto por intermédio de uma cultura jurídica alternativa e pluralista. Diante dos diversos problemas do contexto atual de globalização, neoliberalismo, individualismos exacerbados, desigualdades, rupturas que impactam diretamente no sistema de justiça, o autor propõe:

Tendo em vista esses aspectos, introduz-se a questão central do problema assim exposto: diante da crise e insuficiência da normatividade etnocêntrica ocidental, assentadas nos princípios da cultura liberal-individualista, no sistema produtivo capitalista e na racionalidade colonial determinante de regramentos e controles que homogeneízam, patriarcalizam e subalternizam, em que parâmetros se justifica pensar o direito com base na multiplicidade de saberes locais, de práticas periféricas contra hegemônicas, de outros horizontes interculturais de resistência e de novas formas subjacentes de interlegalidade? A resposta, como hipótese, encontra-se na opção por um "giro descolonial" do direito, em que o pluralismo jurídico assume um lugar privilegiado de contraposição crítica, contribuindo como instrumental analítico e operante para examinar e compreender fenômenos normativos complexos e de diferentes naturezas enquanto sistema de pensamento, de discursividade e de prática social. Assim, o pluralismo jurídico projeta-se como um paradigma para conceber e tratar o direito na própria estrutura social, descentralizando e erradicando o estatalismo universalista da colonialidade (WOLKMER, 2019, p. 2714).

É importante destacarmos as diferenças entre as abordagens dos pluralismos jurídicos, entre aqueles que surgem das tradições indígenas - de formas de resolução de conflitos e normatividades próprias, muitas vezes em conflito 
com as estatais, que, em alguns casos, constituem um "direito indígena”, e aqueles que surgem nas sociedades nacionais, em âmbitos onde o Estado não se faz presente. O pluralismo que nasce com o reconhecimento de um direito indígena está na fonte de importantes reformas constitucionais pluralistas que vemos na América Latina e se relaciona a uma demanda de legitimidade de algo que, historicamente, já está em funcionamento e que se relaciona com as práticas culturais dos povos indígenas. $\mathrm{O}$ reconhecimento do direito indígena e sua capacidade de regulamentação exigem um esforço do Estado nacional em repensar o acesso à justiça de forma pluralista.

Da mesma forma, as práticas e os sentidos de justiça plurais, concernentes a vivências próprias comunitárias e regionais e que se vinculam às estratégias de sobrevivência de vários grupos sociais, contribuem para se pensar o acesso à justiça, contemplando a diversidade da população e um amplo entendimento da cidadania e do reconhecimento de direitos.

Retomando a reflexão acerca dos estudos desenvolvidos sobre o tema no campo do direito, destacamos alguns movimentos formulados desde os Estados Unidos e que adquiriram reconhecimento internacional. O primeiro deles é o Law er Society ${ }^{9}$, inicialmente desenvolvido por um conjunto de pesquisadores estadunidenses, que, ao longo dos anos, vem se expandindo com a integração de estudiosos de diferentes localidades. Marcado por análises críticas e abordagens multi ou interdisciplinares, esse movimento se consolida em uma associação, fundada em 1964, como um grupo de acadêmicos internacional e interdisciplinar, interessado no estudo da lei e suas conexões com os contextos socioculturais, políticos e econômicos. A Law er Economics, por sua vez, tem sua origem nos estudos que conectam o direito com a economia e se consolida com a formação da American Law and Economics Association. A associação é dedicada ao entendimento da lei e sua relação com as políticas públicas e a regulação.

Uma característica que chama a nossa atenção nessas diferentes e complementares abordagens é o fato de que as principais referências e os avanços teóricos alcançados no campo derivam de estudos empíricos de abordagem qualitativa. Observamos que as atualizações teóricas, sejam elas consideradas jurídicas, antropológicas ou sociológicas, exigem uma inserção no campo como

\footnotetext{
9 A expressão "Law er Society" é continuamente objeto de reflexão e crítica, especialmente pela simbologia contida na adição de "direito" e "sociedade". A respeito, Laura Nader (1969) e, posteriormente, Boaventura de Sousa Santos (2016), analisam a melhor adequação de se dizer um "direito em sociedade".
} 
uma imersão estratégica na realidade do acesso à justiça. Consideramos, portanto, que as contribuições com capacidade de atualização teórica derivam da interação com os atores que participam das relações de justiça, aproximando-se das dimensões do que é entendido, em determinado contexto, pelo "acesso".

No Brasil, mais recentemente, o estudo sobre acesso à justiça ganhou um novo impulso com o incentivo e o engajamento de diferentes redes, instituições e grupos de pesquis $\mathrm{a}^{10}$. Desde diferentes polos de investigação, esses estudos têm buscado analisar os obstáculos específicos que a população brasileira enfrenta para acessar o sistema de justiça formal e mobilizar o direito. Fatores como a disponibilidade de informações, a capacidade de conhecer e entender seus direitos e de reivindicar direitos sob o ponto de vista técnico, a cultura das violações de direitos, os paradigmas dos sujeitos de direitos que estão incorporados na prática judicial, o surgimento de novas formas de direitos e reivindicações de justiça e a existência de múltiplos atores envolvidos nas relações locais são alguns dos desafios que identificamos no contexto brasileiro e que nos levam a considerar que a incorporação de teorias sobre o acesso à justiça deve ser acompanhada pelos elementos concretos ou empíricos da realidade em que será incorporada.

Acreditamos, portanto, que uma atualização do debate sobre acesso à justiça é necessária, em tempos de arrefecimento dos processos de exclusão e desigualdades e em contextos em que atritos entre as esferas da política, do direito e da economia geram fissuras no campo da justiça. Essa atualização permeia nossa capacidade de distinguir a ação de reconhecimento de direitos da ação de promoção da justiça e ampliação do horizonte interpretativo desses fenômenos.

\footnotetext{
10 Exemplos são os estudos promovidos e divulgados pela Rede de Estudos Empíricos em Direito (REED), pelo Instituto de Pesquisas Econômicas Aplicadas (IPEA), pelo Departamento de Pesquisas do Conselho Nacional de Justiça (DPJ/CNJ), pelo Centro de Estudos Judiciários do Conselho de Justiça Federal (CEJ/CJF), pelo Centro de Estudos sobre a Justiça da Reforma do Judiciário, Ministério da Justiça (CEJUS/SRJ/MJ), pelo Projeto "Pensando o Direito" da Secretaria de Assuntos Legislativos, Ministério da Justiça (SAL/MJ), pelo Instituto de Pesquisas Direitos e Movimentos Sociais (IPDMS), pelo Centro Brasileiro de Pesquisas (CEBRAP), entre outras iniciativas que surgiram. Ressaltamos, no entanto, que algumas dessas instituições, especialmente públicas, tiveram dificuldades em seguir promovendo estudos e pesquisas sobre o tema no último quinquênio.
} 


\section{Redefinindo o acesso à justiça: a contribuição das pesquisas empíricas, da formação jurídica e das atividades de assistência comunitária}

Quando nos referimos ao acesso à justiça, remetemos ao conjunto de experiências que são vividas em determinados contextos. Não há “justiça” ou seu "acesso" em um sentido abstrato e deslocado; há experiências de justiça e seu acesso. Todas as teorias e reflexões desenvolvidas perdem sentido, se não forem mediadas pela realidade e se não se considerarem as práticas realizadas, os processos de mobilização e luta em torno do acesso à justiça, os bloqueios e desafios que emergem da realidade.

A América Latina tem uma história específica de colonialismo, de exploração e de espoliação de recursos naturais e riquezas, que a torna um importante contexto regional para esse tipo de análise. Especificidades locais e nacionais interagem com as regionais e globais, fazendo com que fenômenos legais e sociais recebam e exerçam influências em diferentes níveis. Falar sobre justiça e seu acesso, nesse contexto, é lidar com um fenômeno sociojurídico local que tem características e dinâmicas ressoadas a partir dos níveis nacional, regional e global. Trata-se de um contexto de intensificação da exploração da força de trabalho, de expansão do capital internacionalizado e do neoliberalismo.

Se considerarmos a emergência de uma nova fase do capitalismo, de "finança mundializada”, tal como analisada por François Chesnais (1996), encontramos uma conjuntura que desafia o pensamento latino-americano a refletir crítica e teoricamente sobre seus limites e suas possibilidades. Particularmente, em relação aos desafios colocados à área do direito pela interpretação da justiça em sua conexão com as relações sociais de dominação, observamos que a justiça constitui uma área estratégica de manutenção dos interesses políticos e econômicos estabelecidos em nossa sociedade capitalista.

Na perspectiva do sistema mundial-colonial moderno marcado pela globalização do capital (CHESNAIS, 1996), a promoção da justiça e a retórica sobre o seu acesso estão nas agendas das preocupações dos Estados-Nação e dos projetos de integração política e econômica. Além disso, constituem pauta importante de organizações e instituições internacionais, como, por exemplo, o Grupo do Banco Mundial, o sistema das Nações Unidas e o Fundo Monetário Internacional (IGREJA; RAMPIN, 2012; RAMPIN, 2018). As Nações Unidas, por exemplo, expressam seu interesse pelo tema ao incluir na Agenda 2030 
para o Desenvolvimento Sustentável, particularmente em seu objetivo no 16 , a importância de promover sociedades pacíficas e inclusivas para o desenvolvimento sustentável, de proporcionar o acesso à justiça para todos e de construir instituições eficazes, responsáveis e inclusivas em todos os níveis.

Também vale a pena destacarmos a atuação do Banco Mundial, intensificada na década de 1990, após as ditaduras empresariais-civis-militares que assolaram a América Latina, na reorganização do sistema de justiça dos países da região. Essa atuação foi consolidada por meio da execução de empréstimos ou assistência financeira à área da justiça, promovendo a produção de conhecimento na área temática e fomentando a elaboração de diretrizes a serem seguidas no processo de reforma das justiças desses Estados, como estratégias de adaptações locais.

Do ponto de vista nacional, a justiça está integrada às políticas governamentais e estatais. É tema estratégico porque se refere não só à forma como os conflitos de interesse na sociedade estão sendo estruturados, mas também ao reconhecimento e à promoção de direitos, à distribuição de bens, aos processos de luta social, ao exercício do poder, entre outras dimensões relevantes.

Nesse contexto nacional, os atores comumente associados ao acesso à justiça estão institucionalizados e correspondem, por um lado, aos órgãos e agentes do Estado e, por outro, aos sujeitos da lei. Trata-se, portanto, de uma justiça institucionalizada e mediatizada pelo Estado. $\mathrm{O}$ acesso à justiça, sob esse ponto de vista, corresponde às condições de entrada e de participação no sistema estatal de resolução de conflitos, perpassando, portanto, ao próprio processo de ser reconhecido como sujeito de direito. Com foco nesse sistema, apropriamo-nos da análise de Cappelletti e Garth (1988, p. 12), para concluir que "[...] o acesso à justiça pode, portanto, ser visto como um requisito fundamental - o mais básico dos direitos humanos - para um sistema judiciário moderno e igualitário que busca garantir e não apenas proclamar os direitos de todos".

Acontece, porém, que, quando nos desafiamos a ampliar nosso horizonte de análise para além dessa associação, percebemos novos atores e, consequentemente, outras relações estabelecidas a partir dos processos de luta e promoção do acesso à justiça na América Latina. Isso porque lidar com a justiça em um determinado contexto implica considerar o conjunto de relações de poder que nele se manifestam. 
Pudemos observar, por exemplo, com as pesquisas realizadas em 2012 e 2014 (INSTITUTO..., 2012, 2015), que, no espaço onde a justiça estatal se realiza, por exemplo, nos fóruns e nas salas de audiência, é constituído um campo de relações de forças, em que são feitas as negociações entre os vários atores sociais, sejam eles pertencentes ao próprio sistema (tais como os integrantes das diversas carreiras jurídicas que atuam no Poder Judiciário) ou não (sujeitos que, embora não sejam nativos do campo judicial, dele participam, eventualmente, quando necessitam participar das práticas judicias em condições de vítimas ou acusados, por exemplo).

Com o desenvolvimento da pesquisa empírica sobre o acesso à justiça em juizados especiais federais (INSTITUTO..., 2012), pudemos notar que, mesmo que nesse espaço judicial paire a defesa da lei e sua efetividade em relação a um caso específico, o que está em disputa, muitas vezes, são demandas repetitivas de cunho comunitário, que se estendem além do universo do poder judicial e que envolvem problemas sociais que impactam nas condições de vida de toda uma coletividade. Nesse contexto, novos atores surgem, representantes diversos dessa coletividade, buscando na justiça uma forma de reconhecimento de seus direitos sociais. A observação de audiências e a realização de entrevistas com cidadãos que ingressaram nessa arena judicial de resolução de disputa permitiram identificarmos os espaços de justiça como lócus de reconhecimento.

Ao nos desafiarmos a olhar para a justiça, mudando o foco do sistema de justiça formal, vemos outras áreas de interesse, outras instituições e outros atores que nos levam a compreender, ainda mais, o universo em que se busca o acesso à justiça, não estritamente judicial ou nativo do sistema de justiça. Em pesquisa recente, em que tivemos a oportunidade de analisar práticas jurídicas universitárias (RAMPIN, 2020), verificamos que a sociedade se mobiliza em outros espaços e em diálogo com outros atores, tais como projetos de educação em direitos, para reivindicar o reconhecimento de sua cidadania. Igualmente, a partir de pesquisa empírica desenvolvida entre os anos 2014 e 2018 (RAMPIN, 2018), com foco nos processos de reforma da justiça na América Latina, passamos a ver novos atores em cena, tais como as instituições financeiras e os organismos internacionais, além de organizações da sociedade civil, que também influenciam na constituição de um campo delimitado no qual se busca justiça e em que novas relações de força e poder são estabelecidas. É a partir dessa perspectiva ampla que podemos ver a justiça como um espaço no qual todos esses movimentos relacionais ocorrem. 
Não devemos esquecer que o contexto latino-americano é marcado por uma diversidade de povos que buscam o reconhecimento de suas diferentes culturas, de diferentes formas de autogoverno, que incluem diferentes modelos de viver, pensar e aplicar justiça. Esses povos, especialmente os indígenas, buscam acesso à justiça a partir de outros modelos legais, novas sensibilidades jurídicas, além do modelo imposto pelos Estados latino-americanos. Esses Estados, por sua vez e em sua maioria, estruturam-se a partir de um modelo de Estado de Direito que, fundado desde a ideia da legalidade e da nação, estabelece as zonas do ser e do não ser. São, portanto, exemplos de pluralismo legal que tantos antropólogos latino-americanos se dedicam a estudar.

No entanto, como exemplo de fenômeno que tem ocorrido globalmente, essa demanda por reconhecimento de outros entendimentos do justo e de justiça não se restringe ao escopo desses povos indígenas, mas também se estende a diferentes esferas, a de outros povos tradicionais, como povos dos campos, das águas e das florestas, e a de populações rurais e urbanas, onde diferentes visões de mundo e de cultura interagem. Portanto, é no âmbito da justiça estatal que diferentes grupos buscam acessar a justiça e garantir seus direitos como coletividades e como cidadãos. E é quando acessam a justiça que os membros desses grupos se encontram em situações de discriminação e racismo, de completa negação de suas especificidades culturais (IGREJA, 2019).

Observamos, portanto, que coexiste essa pluralidade de vozes que demandam reconhecimento no âmbito do acesso à justiça do Estado. A diversidade não é só indígena, mas também regional. Observamos, em países como o Brasil, por exemplo, que diferenças econômicas e socioculturais regionais impactam diretamente no acesso à justiça. Ainda como exemplo, citamos, novamente, nossa participação na pesquisa sobre os juizados especiais federais brasileiros ${ }^{11}$ (IGREJA; RAMPIN, 2012), oportunidade em que constatamos que, embora os juizados tenham aberto as portas para uma população economicamente vulnerável, oferecendo uma resposta mais rápida para suas demandas, sua atuação tem sido pouco eficiente na equalização de direitos, no sentido de conseguir garantir, de maneira mais ampla, a mesma qualidade de justiça para todos. Naquela oportunidade, percebemos que os juizados especiais federais ainda

\footnotetext{
11 Essa pesquisa empírica intitulada: “Acesso à Justiça Federal: dez anos de juizados especiais” foi realizada pela Diretoria de Estudos e Políticas do Estado, das Instituições e da Democracia (DIEST) do Instituto de Pesquisa Econômica Aplicada (IPEA), em parceria com o Centro de Estudos Judiciários do Conselho da Justiça Federal (CEJ/ CJF). As autoras deste texto participaram da pesquisa.
} 
não estavam preparados para atender ao público que pretendiam, considerando, principalmente, os diferentes contextos socioculturais e regionais do País. E, aqui, não estamos adentrando nas especificidades de engajamento individual dos agentes do Estado, mas, sim, na forma pela qual a administração dos conflitos é institucionalizada. A adoção de uma linguagem técnica que não é dominada por grande parte da população, a exigência de vestimentas formais, a adoção de sistemas de segurança, a informatização dos sistemas de identificação, o uso dos “totens" eletrônicos de informação processual, assim como a própria arquitetura de espaços de interação dos cidadãos no Judiciário, como salas de audiências e até mesmo os edifícios, inibem a aproximação dessa população ao judiciário. Quando, finalmente, conseguem ingressar nos juizados, os usuários enfrentam outro problema que é a comunicação não só com os servidores, mas, também, com outros atores que participam das relações formais de justiça. É evidente a dificuldade de comunicação entre os servidores, juízes e os usuários, que não conseguem se exprimir em uma mesma linguagem local, além da dificuldade comum com o vocabulário da justiça. Os usuários, nesse sentido, são sujeitos alheios ao sistema de justiça formal, não são participantes usuais desse campo e, portanto, não compartilham os sentidos e as compreensões com os sujeitos habituais do sistema. Conformam o "outro" no sistema de justiça.

Notamos que a zona do "não ser" nas relações formais de justiça conta, ainda, com outros atores, grupos e instituições, que se movem no sistema articulados com diferentes interesses e sujeitos, e expressam uma ampla diversidade no campo. Os movimentos sociais são exemplos dessa diversidade, na medida em que se constituem sujeitos coletivos de direitos não necessariamente reconhecidos.

Esses atores, em suas interações, desvelam práticas, propõem agendas de modificação e se apresentam de diferentes formas. São exemplos identificados, a partir da pesquisa que promoveu a análise de documentos sobre a experiência brasileira de reforma da justiça (RAMPIN, 2018), os atores que promovem a advocacia popular, as associações profissionais das mais diversas carreiras jurídicas - por exemplo, a Associação dos Juízes pela Democracia (AJD), a Associação Brasileira de Juristas pela Democracia (ABJD), a Associação Advogadas/os Públicos para a Democracia (APD) e o Ministério Público Democrático (MPD) -; as redes de mobilização e democratização da justiça (por exemplo, a Articulação Justiça e Direitos Humanos (JusDH) e o Fórum Justiça); as organizações da sociedade civil; e os movimentos sociais populares e outros coletivos que inovam na forma de sua organização, tais como os projetos de extensão universitária, que potencializam e contextualizam a integração social da instituição de ensino por 
meio de intercâmbios entre a comunidade acadêmica e as comunidades locais, entre outros.

Nesse contexto de múltiplos interesses, algumas perspectivas se destacam no Brasil. Leituras da teoria crítica contemporânea dos direitos humanos (FLORES, 2009a e 2009b; SÁNCHEZ RUBIO, 2007; SOUZA JUNIOR, 2008) elaboram algumas contribuições relevantes para a constituição dessa importante área de estudo e apontam para uma compreensão dos direitos humanos como "lutas sociais concretas da experiência da humanização. São, em resumo, o teste da positivação da liberdade consciente e conquistada no processo de criação de sociedades, na trajetória emancipatória do homem” (SOUZA JUNIOR, 2008, p. 183).

Talita Rampin e Nair Bicalho de Sousa (2016), compartilhando a compreensão de José Geraldo de Sousa Junior (2008 p. 183) sobre os direitos humanos como "lutas sociais concretas da experiência humanizadora. São, em suma, a prova da positivação da liberdade consciente e conquistada no processo de criação de sociedades, na trajetória emancipatória do homem”, apresentam um conceito provisório de acesso à justiça que amplia seu horizonte interpretativo, mas ainda centrado na dimensão do reconhecimento. Segundo as autoras, "falar sobre o acesso à justiça é falar sobre um direito humano instrumental que possibilite o reconhecimento das lutas sociais e seus processos relacionados." (RAMPIN; SOUSA, 2016).

A pluralidade de experiências, no contexto de busca pelo devido acesso à justiça, nos faz afirmar que reconhecer direitos é uma ação diferente da de promover a justiça. Enquanto o primeiro se refere a um movimento de institucionalização, o último denota a aproximação da justiça com os sujeitos, com a garantia de que o espaço a ser acessado trará as condições necessárias para que a interação entre os atores traga o reconhecimento dessa pluralidade de vozes, das diferentes concepções de direitos, da dignidade e da igualdade dos cidadãos. Se pensarmos na justiça como um espaço, somos capazes de ampliar experiências reais de acesso extraído por esses estudos com foco em diferentes práticas e pesquisas empíricas.

A pesquisa empírica, especialmente a qualitativa, tem sido uma ferramenta importante para abordarmos esse espaço jurídico em que se materializam as inter-relações. De maneira especial, a observação de campo dos participantes ${ }^{12}$,

\footnotetext{
12 Segundo Becker (1997, p. 47), o observador participante é quem coleta dados através da participação no cotidiano do grupo ou organização que estuda, observando as pessoas para ver as situações que enfrentam e como reagem a
} 
levando em conta a metáfora de uma aldeia nativa simbólica como forma de delimitação de um campo em que se pretende trabalhar (IGREJA, 2017), permite-nos observar todos os eventos e as experiências dos atores presentes, em diferentes esferas. Essa aldeia não significa necessariamente espaço geográfico definido e tempo, mas está vinculada a todas as inter-relações que podem ser apreendidas nesse espaço criado. Não é, portanto, apenas uma limitação espacial, pois podemos, com a delimitação de um problema, observar os diversos atores envolvidos em múltiplas dimensões e hierarquias, mas todos diretamente relacionados uns com os outros.

O apelo às pesquisas empíricas foi fundamental para que pudéssemos verificar que, além dos possíveis obstáculos burocráticos à garantia de um devido acesso à justiça para a população, havia uma série de fatores, muitos deles subjetivos, relacionados aos entendimentos entre os diversos atores que dificultavam a efetividade do acesso (IGREJA; RAMPIN, 2012). Com base, especialmente, nas observações feitas em fóruns, como parte dos diversos levantamentos realizados em diferentes áreas, como audiências, secretarias, entre outras, ${ }^{13}$ observarmos essa polifonia de discursos, muitas vezes incompreensíveis uns com os outros. Em nome da aplicação de uma lei abstrata, a justiça que se concretiza não considera essa multiplicidade de discursos e desejos presentes nesse espaço, reafirmando estruturas hierárquicas e desigualdades sociais existentes.

Propomos retomar a noção de campo jurídico de Bourdieu para melhor contextualizarmos esse espaço jurídico, a fim de, com base em pesquisas empíricas, sugerir que o acesso à justiça deve ser concebido como o aperfeiçoamento desse espaço, para garantir uma melhor inter-relação e movimento dos diferentes agentes presentes nesse campo.

Podemos formular essa interpretação com a ideia de Pierre Bourdieu de campo jurídico e habitus. Ao se opor às posições formalistas, que afirmam a autonomia absoluta da forma jurídica em relação ao mundo social, mas também o instrumentalismo que vê o direito como uma reflexão ou ferramenta pelas classes dominantes, Bourdieu (1986, p. 3) sugere que as práticas e o discurso

elas. Nessa observação, ele ou ela conversa com todos e busca descobrir suas interpretações do fenômeno em questão.

13 São pesquisas sobre o acesso à justiça de grupos indígenas urbanos na Cidade do México; pesquisa sobre relações raciais e discriminação no campo da justiça (IGREJA, 2004), pesquisa conjunta entre os autores sobre o especial federal do júri no Brasil (INSTITUTO..., 2012), sobre sentenças e medidas alternativas (INSTITUTO..., 2015), além dos artigos dos autores mencionados que se referem à pesquisa. 
jurídico são produto da operação de um campo onde uma lógica específica é duplamente determinada, parcialmente pelas relações de poder específicas que lhe dão sua estrutura e orientam conflitos e parcialmente pela lógica interna dos livros jurídicos que delimitam, a cada momento, o espaço de possibilidades e o universo de soluções devidamente legais.

Segundo Bourdieu, o campo jurídico é de concorrência pelo monopólio do direito de dizer o direito, no qual os agentes se confrontam, portando uma competência inseparavelmente social e técnica, consistindo essencialmente da capacidade socialmente reconhecida de interpretar (de forma mais ou menos livre ou autorizada) um conjunto de textos que incorporem a visão legítima e correta do mundo social (BOURDIEU, 1986, p. 4). Ainda segundo o autor, essa disputa pelo monopólio do acesso aos recursos jurídicos herdados contribuiu para apoiar o recorte social entre o profano e os profissionais e, com o tempo, fazer com que o sistema de normas legais aparecesse, mesmo para aqueles dominados por ele, independentemente das relações de poder no campo que sanciona e consagra. Nessa área, sem sequer perceber, agentes especializados se movem com uma distância neutralizante que, pelo menos no caso dos juízes, é imprescindível para sua função atribuída e está inscrita nas profundezas do habitus da categoria. Por fim, o espaço judicial implica a imposição de uma fronteira entre aqueles que estão preparados para entrar no jogo e aqueles que, quando estão inseridos, permanecem excluídos, incapazes de operar sua conversão mental, para assumir a postura que é exigida nesse espaço social.

Acreditamos que pensar no acesso efetivo à justiça vai além do movimento de entrada nas instituições; é constituir um espaço jurídico não só mais inclusivo, mas mais aberto à autotransformação: um espaço que seja visto como maduro para o diálogo, um espaço de negociação, consciente das diversas posições e preocupações dos diferentes agentes sociais.

Esse espaço jurídico deve ser constantemente renovado e estar atento às mudanças nos contextos sociais e políticos, às novas demandas de direitos e aos novos agentes que são introduzidos no campo. As demandas são múltiplas, assim como os entendimentos do que esperam da justiça. São experiências pessoais movidas para fóruns, habitus diferentes, que, em um contexto democrático, esperam ser reconhecidos. São indivíduos que entram no sistema, com diferentes percepções e entendimentos, que contribuem com novos conhecimentos, novos entendimentos culturais, novas visões de mundo. Mas não são apenas experiências pessoais. Segundo contextos regionais, novos atores, novos profissionais da lei, 
reconhecidos ou não, autorizados ou não, estão envolvidos na busca da defesa dos interesses das partes. Muitas vezes são intermediários dos partidos, por exemplo, representantes de organizações sociais, líderes indígenas ou mesmo simples "tradutores" das questões jurídicas que os acompanham. Ignorar sua presença é ignorar a forma como o acesso à justiça é dado.

E é no espaço do fórum, especialmente na audiência pública, que todos se encontram. E é nesse espaço que o direito de ouvir e dialogar é muitas vezes violado. Juízes aplicam a lei; defensores, advogados, promotores discutem a lei, e as vítimas e os acusados se sentem excluídos de uma justiça que não entendem e não conseguem encontrar maneiras adequadas de se expressar. Portanto, o diálogo não é alcançado, pois as experiências pessoais vão além do caso apresentado e das motivações imediatas, uma vez que implicam um reconhecimento mais amplo das próprias pessoas e dos contextos de onde elas vêm.

A análise desses espaços nos leva a considerar que, mesmo que sugeridos como espaços de direitos, de escuta, eles tornam-se espaços de não diálogo, de não negociação. A inflexibilidade da própria lei e daqueles que a administram, ao repensar quando em contato com aqueles que julgam, impede que a realização da justiça saia do acordo, da negociação e da possível garantia de direitos de todos os envolvidos. Essa conciliação, no entanto, também não pode ser resultado de uma resolução pragmática de um conflito entre as partes, mas se deve refletir em um amplo reconhecimento de direitos, que se transformam nesse espaço incorporando efetivamente as demandas e situações sociais que são colocadas e que têm repercussões mais amplas na comunidade como um todo. É a lei que sai do fórum e reflete sobre a transformação social.

\section{Conclusão}

As diferentes perspectivas analisadas reconhecem o acesso à justiça como essencial para a garantia dos direitos dos cidadãos e para sua completa inclusão na comunidade política. No entanto, com a nossa pesquisa empírica, reconhecemos que devemos refletir melhor sobre múltiplos pontos importantes que revelam a ideia de justiça subjacente nas democracias liberais atuais. Em nossa perspectiva, (1) o acesso à justiça é um elemento essencial nos Estados liberais; (2) o acesso à justiça é garantido aos cidadãos; (3) o acesso à justiça tem uma característica intrínseca em sua capacidade de instrumentalizar a proteção dos direitos desses cidadãos; (4) na contribuição para a defesa desses interesses, o acesso à justiça também auxilia 
os cidadãos a alcançar sua inclusão na comunidade política; e, por último, (5) o acesso à justiça é empregado em relação a um sistema específico de garantia de direitos, sendo o sistema de justiça formal organizado dentro e pelo Estado-Nação.

Em decorrência do exame desses cinco elementos, buscamos compreender alguns dos significados de acesso à justiça. Acreditamos que pensar no acesso à justiça exige um esforço de atualização teórica do debate, de modo a desenvolver novas possibilidades explicativas do fenômeno da justiça e seu acesso, de forma contextual e considerando as relações de poder estabelecidas a partir dele. Esse esforço de análise teórica vem da necessidade de uma melhor contextualização e do questionamento sobre que tipo de acesso à justiça é garantido aos cidadãos. Contemplar o acesso à justiça requer a especificação do debate em contextos distintos (níveis locais, regionais e globais), nos quais a efetivação do direito de acesso obriga a consideração de fatores políticos, históricos e sociais que marcaram o passado, bem como delinearam as relações de poder presentes, e os processos e movimentos de democratização inacabados do Estado e da sociedade. Além disso, pensar no acesso à justiça exige o desenrolar do estudo em novas esferas de complexidade dentro do fenômeno, de modo a não reduzir o acesso à dimensão institucionalizada ou judiciária de sua promoção, e ao menos envolver a investigação de atores, interesses, contextos e teorias sobre o fenômeno.

Nesse sentido, propusemos, neste texto, avançar na concepção de acesso à justiça não apenas como um movimento de institucionalização, mas também como uma transformação do espaço jurídico, onde a justiça é executada. $\mathrm{O}$ acesso à justiça é alcançado pela garantia de um espaço de diálogo e transformação onde a justiça se materializa. Essa transformação somente é possível se houver reposicionamento do próprio sistema de justiça, como parte constituinte da garantia de direitos e resolução de conflitos, e não como parte que se sobrepõe em uma hierarquia. 


\section{Referências}

ABEL, Richard L. Redirecting social studies of law. Law \& Society Review, v. 14, n. 3, p. 805-829, Spring 1980. Edição: Contemporary Issues in Law and Social Science.

BECKER, Howard S. Métodos de pesquisa em Ciências Sociais. São Paulo: Ed. Hucitec, 1997.

BOURDIEU, Pierre. Le sens pratique. Paris : Editions de Minuit, 1980.

BOURDIEU, Pierre. La force du droit : éléments pour une sociologie du champ juridique. Actes de la Recherche en Sciences Sociales, v. 64, p. 3-19, sep. 1986. Edição: De quel droit?

CAPPELLETTI, Mauro; GARTH, Bryant. Acesso à justiça. Porto Alegre: Sérgio Antônio Fabris, 1988.

CHENAUT, Victoria; SIERRA, María Teresa. Los debates recientes y actuales en la Antropología Jurídica: las corrientes anglosajonas. In: CONGRESO DE LA RED LATINOAMERICANA DE ANTROPOLOGÍA JURÍDICA EN HONOR A JANE COLLIER, 5., 1986, Oaxtepec, Morelos, México. Antología: grandes temas de la Antropología Jurídica. Oaxtepec, Morelos, México: Red Lationamericana de Antropologia Jurídica, 2006. p. 27-58. Disponível em: https://laasociacion. files.wordpress.com/2017/09/antropologc3ada-jurc3addica1.pdf. Acesso em: 18 out. 2021.

COLLIER Jane, El derecho zinacanteco. Procesos de disputar en un pueblo indígena de Chiapas, México, CIESAS, 1995.

CHESNAIS, François. A mundialização do capital. São Paulo: Xamã, 1996.

COMAROFF, John L.; SIMON, Roberts. Rules and processes: the cultural logic of ispute in an african context. Chicago: The University of Chicago Press, 1981. 302 p.

DEZALAY, Yves; GARTH, Bryant. The internationalization of palace wars: lawyers, economists, and the contest to transform Latin American states. Chicago: The University of Chicago Press, 2002. 302 p. (Chicago Series in Law and Society). 
FARROW, Trevor C. W. What is access to justice? Osgoode Hall Law Journal, v. 51, n. 3, p. 957, 2014. Disponível em: https://papers.ssrn.com/sol3/papers. cfm?abstract_id=2503501. Acesso em: 19 out. 2021.

HERRERA FLORES, Joaquín. A (re) invenção dos direitos humanos. Florianópolis: Fundação Boiteux, 2009a. 231 p.

HERRERA FLORES, Joaquín. Teoria crítica dos direitos humanos: os direitos humanos como produtos culturais. Rio de Janeiro: Lumen Juris, 2009b. 229 p.

GARTH, Bryant; CAPPELLETTI, Mauro. Access to justice: The newest wave in the worldwide movement to make rights effective. Buffalo Law Review, v. 27, p. 181-292, 1978. Disponível em: http://www.repository.law.indiana.edu/ facpub/1142. Acesso em: 19 out. 2021.

GARTH, Bryant. Comment: A revival of access to justice research? In: SANDEFUR, R. L. (ed.). Access to justice. Bingley, UK: Emerald JAI, 2009. (Sociology of Crime, Law And Deviance, v. 12). p. 255-260.

IGREJA, Rebecca Lemos. Desigualdade e a construção do outro pela extremadireita: projeto de pesquisa. [Brasília]: Universidade de Brasília, 2020. Programa de Iniciação Científica.

IGREJA, Rebecca Lemos. O Direito como objeto de estudo empírico: o uso de métodos qualitativos no âmbito da pesquisa empírica em Direito In: MACHADO, Maíra Rocha (org.). Pesquisar empiricamente o Direito.1 ed. São Paulo: Rede de Estudos Empíricos em Direito, 2017. p. 11-37. Disponível em: https:// reedpesquisa.org/wp-content/uploads/2019/04/MACHADO-Mai\%CC\%81raorg.-Pesquisar-empiricamente-o-direito.pdf. Acesso em: 19 out. 2021.

IGREJA, Rebecca Lemos. Justiça, identidade e juventude indígena urbana: um estudo sobre os processos organizativos na Cidade do México. Anuário Antropológico, v. 44, n. 2, p. 129-158, 2019. Disponível em: https://journals. openedition.org/aa/4011. Acesso em: 19 out. 2021.

IGREJA, Rebecca Lemos. Justicia y diferencia étnica: el reconocimiento étnico en el contacto de los grupos indígenas migrantes en la ciudad de México con la administración de justicia capitaliana. Revista Mexicana de Ciencias Políticas y Sociales, v. 46, n. 188-189, p. 169-189, 2004. Disponível em: http://www.revistas. unam.mx/index.php/rmcpys/article/view/42419/38541. Acesso em: 19 out. 2021. 
IGREJA, Rebecca Lemos; RAMPIN, Talita. Acesso à justiça e desigualdades: perspectivas latino-americanas. In: IGREJA, Rebecca Lemos; NEGRI, Camilo (org.) Desigualdades globais e justiça social: interfaces teóricas, acesso à justiça e democracia. Brasília, DF: Faculdade Latino-Americana de Ciências Sociais, 2021a.v. 1, p. 214-240. Disponível em: https://dialnet.unirioja.es/servlet/ libro? codigo $=831801 \&$ orden $=0$ \&info=open_link_libro. Acesso em: 19 out. 2021 .

IGREJA, Rebecca; RAMPIN, Talita. Acesso à justiça e exercício da jurisdição em tempos de pandemia: projeto de pesquisa. [Brasília]:Universidade de Brasília, 2021b.

IGREJA, Rebecca; RAMPIN, Talita Tatiana Dias. Acesso à justiça na América Latina: reflexões a partir dos juizados especiais federais do Brasil. Revista de Estudos e Pesquisas sobre as Américas, Brasília, v. 6, n. 1, p. 19-35, 2012. Disponível em: https://periodicos.unb.br/index.php/repam/article/ view/19537/18067. Acesso em: 19 out. 2021.

IGREJA, Rebecca Lemos; SIERRA, María Teresa. Pluralismo jurídico e direitos indígenas na América Latina: fundamentos e debates. Revista da Faculdade de Direito da UFG, v. 44, n. 3, 2020. Disponível em: https://www.revistas.ufg. br/revfd/article/view/66516. Acesso em: 19 out. 2021.

INSTITUTO DE PESQUISA ECONÔMICA APLICADA. Acesso à Justiça Federal: dez anos de juizados especiais. Brasília: Conselho da Justiça Federal, Centro de Estudos Judiciários, 2012. 228 p. (Série pesquisas do CEJ, 14). Disponível em: https://corteidh.or.cr/tablas/28568.pdf. Acesso em: 19 out. 2021.

INSTITUTO DE PESQUISA ECONÔMICA APLICADA. A aplicação de penas e medidas alternativas: relatório de pesquisa. Rio de Janeiro, 2015. 93 p. Disponível em: https://www.ipea.gov.br/portal/images/stories/PDFs/ relatoriopesquisa/150325_relatorio_aplicacao_penas.pdf. Acesso em: 19 out. 2021.

JUNQUEIRA, Eliane Botelho, Acesso à Justiça: um olhar retrospectivo, Revista Estudos históricos, v. 9, n. 18, Justiça e cidadania, 1996.

LIMA, Roberto Kant de. Ensaios de Antropologia e de Direito: acesso à justiça e processos institucionais de administração de conflitos e produção da verdade jurídica em uma perspectiva comparada. 1. ed. Rio de Janeiro: Lumen Juris, 2008. 289 p. 
LIMA, Roberto Kant de. Polícia, justiça e sociedade no Brasil: uma abordagem comparativa dos modelos de administração de conflitos no espaço público. Revista de Sociologia e Política, Curitiba, n. 13, p. 23-38, nov. 1999. Disponível em: https://revistas.ufpr.br/rsp/article/view/39241/24062. Acesso em: 19 out. 2021.

LIMA, Roberto Kant de. Sensibilidades jurídicas, moralidades e processo penal: tradições judiciárias e democracia no Brasil contemporâneo. Revista de Estudos Criminais, v. 11, n. 48, p. 7-33, 2013.

MERRY, Sally. Legal Pluralism, Law \& Society Review Vol. 22, No. 5, p. 869896, 1988.

MOORE, Sally Falk. Social facts and fabrications: "Customary" Law on Kilimanjaro, 1880-1980. Cambridge: Cambridge University Press, 1986. (Lewis Henry Morgan Lectures, 1981).

NADER, Laura; Wenner-Gren Foundation for Anthropological Research. Law in culture and society. Chicago: Aldine Publishing Company.1969.

OLIVEIRA, Luis Roberto Cardoso de. Direito legal e insulto moral: dilemas da cidadania no Brasil, Quebec e EUA. 2. ed. Rio de Janeiro: Garamond Ltda, 2011.

RAMPIN, Talita Tatiana Dias. Estudo sobre a reforma da justiça no Brasil e suas contribuições para uma análise geopolítica da justiça na América Latina. 2018. 436 f. Tese. (Doutorado em Direito, Estado e Constituição) Faculdade de Direito, Universidade de Brasília, Brasília, 2018. Disponível em: https://repositorio.unb.br/handle/10482/32203. Acesso em: 19 out. 2021.

RAMPIN, Talita. Práticas jurídicas universitárias e acesso à justiça, projeto de pesquisa, Programa de Iniciação Científica, Universidade de Brasília, 2020.

RAMPIN, Talita Tatiana Dias; SOUSA, Nair Heloisa Bicalho de Sousa. Para uma agenda democratizante da justiça: um olhar desde a educação em direitos humanos sobre a justiça de transição. In: REBOUÇAS, Gabriela Maia; SOUSA JUNIOR, José Geraldo de; CARVALHO NETO, Ernani Rodrigues de (org.). Experiências compartilhadas de acesso à justiça: reflexões teóricas e práticas. Santa Cruz do Sul: Essere nel Mondo, 2016.

RHODE, Deborah L. Access to justice: an agenda for legal education and research. Journal of Legal Education, v. 62, n. 4, p. 531, May 2013. 
SADEK, Maria Tereza. Acesso à justiça. São Paulo: Konrad Adenauer Stiftung, 2001. 278 p.

SÁNCHEZ RUBIO, David. Repensar derechos humanos: de la anestesia a la sinestesia. Sevilla: MAD, 2007. (Universitaria Textos Jurídicos).

SANDEFUR, Rebecca L. Access to civil justice and race, class and gender inequality. Annual Review of Sociology, v. 34, p. 339-58, Aug. 2008.

SANDEFUR, Rebecca L. "Access to what?" Daedalus: The Journal of the American Academy of Arts and Sciences, v. 148, n. 1, p. 49-55, winter 2018. Disponível em: https://www.amacad.org/sites/default/files/publication/downloads/19_Winter_ Daedalus_Sandefur.pdf. Acesso em: 19 out. 2021.

SANTOS, Boaventura de Sousa. The law of the oppressed: the construction and reproduction of law in Passargada. Law \& Society Review, v. 12, n. 1, p. 5-126, Automn 1977.

SANTOS, Boaventura de Sousa. Introdução à sociologia da administração da justiça. Revista Crítica de Ciências Sociais, n. 21, p. 11-37, nov. 1986. Disponível em: https://eg.uc.pt/bitstream/10316/10797/1/Introdu\%C3\%A7\%C3\%A3o\%20 \%C3\%A0\%20Sociologia\%20da\%20Administra\%C3\%A7\%C3\%A3o\%20da\%20 Justi\%C3\%A7a.pdf. Acesso em: 19 out. 2021.

SANTOS, Boaventura de Sousa. O direito dos oprimidos. São Paulo: Cortez, 2014. 432 p. (Sociologia crítica do direito, v. 1)

SANTOS, Boaventura de Sousa. As bifurcações da ordem: revolução, cidade, campo e indignação. São Paulo: Cortez, 2016. 406 p. (Sociologia crítica do direito, v. 3)

SIERRA, María Teresa. Derecho indígena y mujeres: viejas costumbres, nuevos derechos. In: PÉREZ-GIL ROMO, Sara Elena; RAVELO BLANCAS, Patricia (coord.). Voces disidentes: debates contemporáneos en los estudios de género en México. México: CIESAS/ Cámara de Diputados, Porrúa, 2004. p. 113-149. Disponível em: https://mariateresasierra.files.wordpress.com/2018/05/2004derecho-indicc81gena-y-mujeres.pdf. Acesso em: 19 out. 2021. 
SIERRA, María Teresa; IGREJA, Rebecca Lemos. Neocolonialismo y la justiciabilidad de los derechos indígenas: introducción. Cahiers des Amériques Latines, n. 94, 2020. Este fascículo publica o dossiê organizado por María Teresa Sierra e Rebecca Lemos Igreja intitulado "Nuevos retos del pluralismo jurídico en América Latina”. Disponível em: https://journals.openedition.org/cal/11793. Acesso em: 19 out. 2021.

SOUSA JUNIOR, José Geraldo de. Direito como liberdade: o direito achado na rua. Experiências populares emancipatórias de criação do direito. Tese de Doutorado em Direito do Programa de pós-graduação da Faculdade de Direito, Universidade de Brasília, 2008 Disponível em: https://repositorio.unb. $\mathrm{br} / \mathrm{handle} / 10482 / 1401$.

STARR, June; COLLIER, Jane F. Introduction: dialogues in Legal Anthropology. In: (ed.). History and power in the study of law: new directions in legal Anthropology. Ithaca, NY: Cornell University Press, 2018. p. 1-28. Disponível em: https://www.degruyter.com/document/doi/10.7591/9781501723322-003/ html. Acesso em: 19 out. 2021.

STAVENHAGEN, Rodolfo; ITURRALDE, Diego A. (coord.). Entre la ley y la costumbre: el derecho consuetudinario en América Latina. México: Instituto Interamericano Indigenista; San José, Costa Rica: Instituto Interamericano de Derechos Humanos, 1990. 388 p.

STAVENHAGEN, Rodolfo. Los pueblos originarios: el debate necesario. Buenos Aires: CTA Ediciones: CLACSO: Instituto de Estudios y Formación de la CTA, 2010. 176 p. (Pensamientos / Norma Fernández; 5). Disponível em: http:// biblioteca.clacso.edu.ar/clacso/coediciones/20101117084419/Stavenhagen.pdf. Acesso em: 29 out. 2021.

WOLKMER, Antonio Carlos. Pluralismo jurídico: um referencial epistêmico e metodológico na insurgência das teorias críticas no direito. Revista Direito e Práxis, v. 10, n. 4, p. 2711-2735, dez. 2019. Disponível em: https://www.epublicacoes.uerj.br/index.php/revistaceaju/article/view/45686/31167. Acesso em: 21 fev. 2021. 